\title{
Da metáfora oceânica à revolução demográfica
}

\author{
Guélmer Júnior Almeida de Faria*
}

\begin{abstract}
MORLAND, Paul. A maré humana: a fantástica história das mudanças demográficas e migrações que fizeram e desfizeram nações, continentes e impérios. Rio de Janeiro: Zahar, 2019. 384 p.
\end{abstract}

Nos últimos anos, as mudanças mundiais geoestratégicas surtiram efeitos sobre várias ordens e dinâmicas, nos âmbitos social, político, ambiental, econômico e cultural. Não por acaso, essas transformações mudaram o curso da história de toda a humanidade. Nesse livro, Paul Morland (2019) concebe tais mudanças como uma metáfora oceânica, “o turbilhão demográfico": a maré humana - "o grande fluxo da humanidade, crescendo aqui, refluindo ali, e de como isso deu uma contribuição vasta e, com demasiada frequência, despercebida ou subestimada para o curso da história” (MORLAND, 2019, p. 14).

0 autor delineia o tamanho dessas transformações com base no que chama de uma "revolução demográfica" - o grande fluxo da humanidade, cujos subsídios são vastos (e, às vezes, não ter em grande conta) para o curso da história. “Ele foi, portanto, revolucionário em termos tanto de tempo quanto de espaço: de tempo porque foi um crescimento de população não somente célere, mas sustentável; de espaço porque estabeleceu um padrão que deveria ser reproduzido no mundo todo" (MORLAND, 2019, p. 52). Morland recorre ao peso dos números citando exemplos básicos do tamanho e aumento da população mundial, do ano 47 antes de Cristo até 1837, período em que a população mundial passou de 250 milhões para 1 bilhão de habitantes. De 1837 até os dias atuais, esse número supera os 7 bilhões.

\footnotetext{
*Universidade Federal de Viçosa (UFV), Viçosa-MG, Brasil (guelmerjrf@yahoo.com.br; https://orcid.org/0000-00032089-3064).
} 
Logo no prefácio, é destacado o papel da história e seus eventos para a compreensão dos estudos populacionais. Morland é convergente com a postura de Reher (1997), de que "a pessoa que escreve sobre, por exemplo, a história da peste está fazendo tanto demografia histórica como história da população”. A demografia histórica, portanto, deve adotar um enfoque proporcional nas análises da história da população.

0 autor ainda sinaliza que a ascensão e a queda do Império Britânico, o surgimento dos Estados Unidos como superpotência e os desafios globais, como o nazifascismo e a Guerra Fria, desencadearam uma visão demográfica assentada no controle de seus próprios números. A demografia deixou de ser a disciplina que mudava mais lentamente para tornar-se a de transformação célere. Tendências populacionais não se movem mais a passos lentos, com ocasionais interrupções chocantes, como a peste negra e a Covid-19. Fecundidade e mortalidade caem com crescente rapidez e transições, que outrora levavam gerações, agora ocorrem em décadas.

O livro está dividido em três partes, com nove capítulos, além de dois apêndices. Ademais, a obra apresenta, na composição do seu conteúdo, notas, referências, agradecimentos e índice remissivo. A primeira parte conta com uma nota introdutória, evidenciando como a vida de uma sociedade pré-industrial mudou com o advento da sociedade industrial e como a metáfora oceânica da maré humana reflete-se no papel da população na história. "O livro não argumenta que as grandes tendências populacionais - elevação e queda das taxas de nascimento e morte, aumento e diminuição da população, surtos de migração determinam a história" (MORLAND, 2019, p. 15). 0 autor defende que a demografia está profundamente enraizada na vida e a população deve ser compreendida ao lado de outros fatores causais, como inovação tecnológica, progresso econômico, crenças e ideologias cambiantes. Morland conclui a introdução afirmando que a história da maré humana deveria ser contada com todas as suas imperfeições, mas também pelo que é: nada menos que um triunfo da humanidade.

Na segunda parte do livro, Morland definiu a maré em direção contrária, do ponto mais baixo para o mais alto, no caso europeu. 0 rápido crescimento da produção industrial e a grande explosão populacional teriam fornecido ondas para as exportações e permitiram que a Grã-Bretanha tomasse de assalto o mundo inteiro. A explosão demográfica possibilitou primeiro que os povos da Grã-Bretanha, e depois mais amplamente o povo da Europa, dominassem o globo. Em seguida, ela desempenhou um importante papel ao forçar sua retirada. Triunfo dos anglo-saxões, desafios do alemão e russo, o surgimento da "Grande Raça”, o baby boom, a imigração em massa e a Rússia e o Bloco do Leste Europeu são alguns eventos históricos utilizados pelo autor para explicar a "revolução demográfica", tendo explodido na Grã-Bretanha no início do século XIX e se espalhado pela Europa, inclusive na Rússia, e pelas terras de conquista e colonização europeias.

A retórica desenvolvida no livro destaca que o transbordamento da revolução populacional, no curso dos últimos 200 anos, mudou o mundo. Alguns fenômenos são latentes dessa revolução demográfica, como a história da ascensão e queda de Estados e de grandes 
mudanças no poder e na economia, que terão rebatimentos nos modos de vida individuais. Como exemplos, têm-se: mulheres britânicas que, no prazo de uma geração, pararam de esperar que a maioria de seus filhos morresse antes da idade adulta; idosos japoneses sem filhos morrendo sozinhos em seus apartamentos; crianças africanas atravessando 0 Mediterrâneo à procura de oportunidades de vida.

Paul Morland demonstra os três argumentos centrais que esclarecem essa revolução demográfica: a queda vertiginosa na mortalidade infantil; a desaceleração da fecundidade (mas com maior expectativa de vida ao nascer); e o fenômeno das migrações. Essas transformações já decorriam desde o início do século XIX, mas, quando se revelam verdadeiramente globais, após 1945, causaram um tsunami, provocando mudanças sociais intensas e demudando tudo - da geoestratégia à macroeconomia, da demanda de berços à necessidade de túmulos. 0 "turbilhão demográfico" espalhou-se pelo mundo, a partir das Ilhas Britânicas, mas rapidamente expandiu-se para as demais regiões do planeta, alterando formas de vida e criando novas, fato que o autor chama atenção: "de que a vida ficou imensuravelmente melhor para bilhões de pessoas" (MORLAND, 2019, p. 14). A problematização da revolução demográfica, assim como as análises demográficas dos fenômenos que chegam a ser interpretados como riscos globais ou catástrofes, deve julgar seus precedentes a partir de uma perspectiva histórica e atual.

Ao final, na terceira parte do livro, a maré torna-se global e vai para além da Europa. Aqui, a metáfora oceânica origina o "encontro das águas”. Japão, China e Ásia Oriental mostram-se como gigantes, por deterem $1 / 3$ da população mundial, e a diminuição no século XX de "famílias de menor tamanho ocasionando as sociedades mais idosas e envelhecidas e finalmente em um processo de encolhimento em muitas outras partes do mundo" (MORLAND, 2019, p. 254). 0 autor ainda esboça uma demografia da instabilidade com o Oriente Médio e o norte da África, apontando que, nessas regiões, embora os dados podem ser imperfeitos e suspeitos, foi somente com o processo de modernização que a demografia assumiu uma jornada reconhecível. A partir da metade do século XX, a modernização fragmentada e desigual da região começou a ser mais regular, uniforme e poderosa, resultando no "encontro das águas". Tal padrão de repetição só é visto, em primeiro lugar, na Grã-Bretanha, mais de um século antes, e, posteriormente, replicado em todo o mundo, embora em ritmo muito mais acelerado. Otimista, o autor mostra que, mesmo essa região apresentando muitos problemas associados à instabilidade política, à falta de democracia e de direitos humanos e a um fracasso no desenvolvimento socioeconômico, quando sua demografia assemelhar-se à da Europa - perspectiva que parece mais próxima agora do que algumas décadas atrás -, o Oriente Médio poderá ser o melhor dos mundos tanto quanto a Europa hoje.

No capítulo final da terceira parte, Morland analisa a maré humana sob o sol, em que questiona: nada de novo sob o sol? Ou seja, as regiões que não haviam sido abordadas ainda no livro, América Latina e Ásia Meridional, apresentam alguma novidade ou seguem o curso de um padrão revolucionário demográfico? São duas regiões vastas, complexas e completamente 
diferentes. 0 peso dos números para a América Latina evidencia uma reversão de maré alta para maré baixa. Em 2015, a América do Sul tinha mais de 400 milhões de habitantes, a Central, um pouco mais de 170 milhões, e o Caribe, pouco mais de 40 milhões. De fato, devido à migração para a América do Norte, a população não crescia, apesar de apresentar alta taxa de fecundidade. Paul Morland exemplifica que o Brasil é de longe o maior país da região, tanto geograficamente quanto em termos de população, abrigando cerca de $1 / 3$ da população total da América Latina e metade da população da América do Sul. 0 autor destaca seus processos de desenvolvimento entre regiões avançadas e atrasadas e chama a atenção para o processo de urbanização, no início do século XXI - 3/4 do Brasil já eram urbanos, denotando padrão típico da maioria dos países ao redor do mundo. Ressalta-se ainda a queda da fecundidade no Brasil, com iniciativas de planejamento familiar e disseminação dos meios de comunicação (com especial atenção para a TV e as telenovelas). Morland encerra evidenciando que, mesmo com a queda da fecundidade, a expectativa de vida se alongou.

Na rota do fenômeno da revolução demográfica, Morland chega à Ásia Meridional, cuja população alcança 1,75 bilhão de pessoas, próximo de $1 / 4$ de toda a humanidade. A Índia destaca-se como o país mais populoso e tem sua queda de fecundidade relacionada ao maior desenvolvimento econômico, à crescente alfabetização feminina e à urbanização. Além do mais, o governo indiano desempenhou uma linha dura em relação ao controle populacional. Essas medidas lhe garantem usufruir de um bônus demográfico, ao passo que a China enfrenta um colapso em sua reposição de força de trabalho e envelhecimento populacional.

A fronteira final para a transição demográfica, para o autor, está na África Subsaariana. Destacam-se números, como, por exemplo, dos 48 Estados e territórios com taxas de fecundidade de quatro ou acima, 41 estão na África Subsaariana. Ademais, há nove dos dez países com as mais elevadas taxas de fecundidade. Todos os 30 países com a mais baixa expectativa de vida estão na região. Isso faz com que a região encontre-se em estágio inicial da transição demográfica e, portanto, o maremoto está em sua maior intensidade.

Morland apresenta um panorama da demografia integrada ao futuro por três cores: "mais grisalho", “mais verde" e "menos branco". Claramente, tem-se uma referência aos fenômenos do envelhecimento, das questões de sustentabilidade ambiental e da integração étnica. Trata-se, portanto, de uma análise focada nas fantásticas mudanças demográficas e migrações que compuseram e reordenaram nações, continentes e impérios, por meio da comparação entre países de diferentes regiões para entender as dinâmicas e especificidades sociais e culturais.

Ao final das ondas marítimas e encerrando o livro, Paul Morland guia o leitor para dois apêndices: o primeiro conta como se calcula a expectativa de vida; e o segundo, a taxa de fecundidade total. Esses dois exercícios práticos revelam como a demografia é importante para a vida das pessoas. 0 autor argumenta que a demografia também importa mais agora do que no passado, porque as políticas públicas ganharam cada vez mais a dimensão étnica na era moderna. Os pesos dos números, segundo ele, "são nada mais, nada menos do que a soma de esperanças, amores e medos de cada ser humano individual” (MORLAND, 2019, p. 48). 
Em uma primeira vista, o livro pode ser encarado como uma obra direcionada para os demógrafos. Porém, o debate proposto sobre a revolução demográfica e a história das mudanças demográficas e migrações amplia o escopo para as ciências humanas. A leitura também é recomendada para os reformuladores de políticas públicas, que serão progressivamente acionados na elaboração de estratégias para lidar com problemas individuais cada vez mais coletivos da humanidade.

A obra também sinaliza para pensar a nossa história do tempo presente, o cenário mundial do início de 2020, marcado por um surto de uma misteriosa pneumonia causada por uma variação do coronavírus (Covid-19), ${ }^{1}$ cujo primeiro caso ocorreu em Wuhan, na China, em dezembro de 2019. Os casos da transmissão global, logo, espalharam-se por todos os continentes, o que caracterizou um surto. No final de janeiro de 2020, a Organização Mundial de Saúde (OMS) declarou a situação como uma emergência em saúde pública de interesse internacional. Diante disso, Morland traz boas pistas para pensarmos como a interação dos seres humanos através do tempo e do espaço é, simplesmente, vasta e complexa. Os grandes progressos em condições materiais, nutrição, habitação, saúde e educação, que se espalharam pela maior parte do globo desde o início do século XIX, foram claramente ondas impulsionadas pela economia, mas também por "ondas de superfície"2 da demografia.

\section{Referências}

MORLAND, P. A maré humana: a fantástica história das mudanças demográficas e migrações que fizeram e desfizeram nações, continentes e impérios. Rio de Janeiro: Zahar, 2019.

REHER, D. S. Desafios e conquistas da demografia histórica no final do século. Revista Brasileira de Estudos de População, São Paulo, v. 14, jan./ dez., p. 101-124, 1997.

\section{Sobre 0 autor}

Guélmer Júnior Almeida de Faria é pós-doutorando na Universidade Federal de Viçosa (UFV) e doutor em Desenvolvimento Social pela Universidade Estadual de Montes Claros (Unimontes).

\section{Endereço para correspondência}

Avenida Nelson Viana, 1157, Morada do Parque 39401-354 - Montes Claros-MG, Brasil

\footnotetext{
${ }^{1}$ No mundo já atingiu mais de 14 milhões de pessoas. No Brasil, dois milhões de infectados com mais de 80 mil óbitos (OMS, agosto de 2020).

${ }^{2}$ Ocorrem na interface oceano/atmosfera.
} 